\title{
Morphologieal and Biologieal Properties of a New Coronavirus Associated with Diarrhea in Infant Mice
}

\author{
By \\ K. Sugtyama and Y. Amano \\ Department of Microbiology and Central Laboratory, \\ Akita University School of Medicine, \\ Akita, Japan \\ With 7 Figures
}

Accepted September 26, 1980

\begin{abstract}
Summary
Biological and morphological properties of a virus, isolated from the intestine of infant mice with clinical signs of diarrhea and designated as diarrhea virus of infant mice (DVIM), were examined. The first infective virus was detected on the cells 4 hours post infection, followed by rapid release of the virus into the culture fluids. Virus-induced syncytia in BALB/c-3 T3 cell cultures caused hemadsorption at $4^{\circ} \mathrm{C}$ and viral antigens were shown to be located in the cytoplasm of the syncytia by immunofluorescent techniques. By scanning electron-microscopy, budding virus-like particles were detected on the surface of virus-induced syncytia. Morphologically the virus was shown to be enveloped and approximately $100 \mathrm{~nm}$ in diameter. Two types of projections were demonstrated, one type of projection was club-shaped, $20 \mathrm{~nm}$ in length and the other type was small, granular, $5 \mathrm{~nm}$ in length. The latter type of projection might be the basal part of the clubshaped type and related to the hemagglutinating activity.
\end{abstract}

\section{Introduction}

Among the coronaviruses, there are strains that cause intestinal infections leading to enteritis and diarrhea in swine $(11,25)$, calves $(4,19,23)$, rodents $(21)$ and possibly man (9).

Recently, a new viral agent (DVIM) was isolated from an infant mouse with diarrhea, by the utilization of cultured cells. It has also been shown by complement fixation tests that this new isolate is antigenically related to known coronaviruses, avian infectious bronchitis virus (IBV) and mouse hepatitis virus strain-2 (MHV-2). The viral agent was propagated in BALB/c-3T3 cells with the formation of syncytia and caused hemadsorption and hemagglutination of mouse or rat erythrocytes (24). 
The present report describes the morphology and some biological characteristics of the new coronavirus-like agent (DVIM), and shows that some of the properties of this virus are unique compared to the previously studied coronaviruses $(18,26)$.

\section{Materials and Methods}

Virus and Cell Cultures

A virus isolated from the intestine of an infant mouse with clinical signs of diarrhea, designated DVIM, was generously provided by Dr. Kozaburo Sato (Central Laboratory of Shionogi Pharm. Co., Osaka, Japan). Growth and purification of DVIM have been previously described (24).

\section{Hemadsorption and Hemagglutination}

Hemadsorption and hemagglutination (HA) assays were performed as previously described (24), using 0.5 per cent mouse erythrocytes in PBS containing 0.3 per cent bovine serum albumin.

\section{Scanning Electron Microscopy (SEM)}

Cells were cultured on glass cover-slips $(6 \times 23 \mathrm{~mm})$ infected with DVIM as described above. At designated intervals cover-slips treated or untreated with erythrocytes were rinsed five times with cold-PBS, fixed with glutaraldehyde (4 per cent in PBS), dried in a critical-point dryer and coated with gold-palladium alloy in vacuum $\left(10^{-6}\right.$ torr $)$ and examined by SEM.

\section{Virus Growth and Assay}

Culture tubes containing approximately $10^{6}$ of BALB/e-3T 3 cells were inoculated with $10^{7} \mathrm{TCID}_{50}$ of DVIM. After one hour of virus adsorption at $4^{\circ} \mathrm{C}$, the tubes were washed five times with PBS and fed with $1 \mathrm{ml}$ of maintenance medium, then incubated on roller drum at $37^{\circ} \mathrm{C}$. At various time intervals of incubation, the culture media of five tubes were collected randomly and examined for extracellular virus (ECV). The same tubes were washed five times with PBS, and the cells were disrupted with $1 \mathrm{ml}$ of maintenance medium by two cycles of freezing and thawing. The supernates of the dismpted cells were collected after centrifugation at $2000 \times g$ for 10 minutes and the virus contained in the supernate was designated cell-associated virus (CAV). The infectivity of ECV and CAV was assayed as described above, and expressed as a number of median tissue culture infectious doses $\left(\right.$ TCID $\left._{50}\right)$ per $0.1 \mathrm{ml}$.

\section{Measurement of the Cell-Fusion Ratio}

Infected cell cultures on coverslips, were harvested at various time intervals post infection (p.i.), fixed with 70 per cent ethanol and stained with Giemsa's solution. The cell-fusion ratio was caleulated, based on the total nuclei per fused cells against total nuclei counted in the same microscopic viewing area.

\section{Hyperimmune Serum}

Hyperimmune serum against purified DVIM was prepared in a rabbit as follows: For the first and second inoculation, virus was injected intramuscularly with an equal volume of complete Freund's adjuvant within a three-week interval, and a booster injection was given without adjuvant three weeks after the second-injection. Antibody titer for the immune serum was determined as 2,048 and 1,024 in hemagglutination and neutralization test respectively.

\section{Immunofluorescent Staining}

Infected cell cultures on coverslips were fixed with acetone at $4^{\circ} \mathrm{C}$ for 15 minutes and the indirect method using rabbit anti-DVIM serum and fluoresceine isothiocyanate-conjugated goat anti-rabbit globulin was applied. 


\section{Electron Microscopy}

Virus samples were negatively stained with 2 per cent potassium phosphotungstate (pH 6.5) and examined in JEM-100 B electron microscope.

\section{Results}

\section{Cytopathic Effect of DVIM}

The cytopathic effect of DVIM was characterized by the formation of syncytia in BALB/c-3T3 cell cultures.

When cells were infected at low multiplicities of infection (approximately, MOI $=0.1$ ), small syncytia were detectable at 8 hours p.i. At 18 to 24 hours p.i., all areas of the cell sheet consisted of syncytia. Subsequently, syncytial lysis began from the center of each syncytium and progressed toward the periphery. The relationships between virus production and formation of syncytium were examined by a comparison of $\mathrm{HA}$ titers of the culture fluid with the cell-fusion ratio during the replicative cycle of the virus (Fig. 1). As can be seen from Fig. 1, HA activity was detected at 8 hours p.i. but development of syncytium lagged behind. Maximum syncytium development occurred between 12 and 18 p.i. HA titers reached a peak by 11 hours p.i. and remained constant.

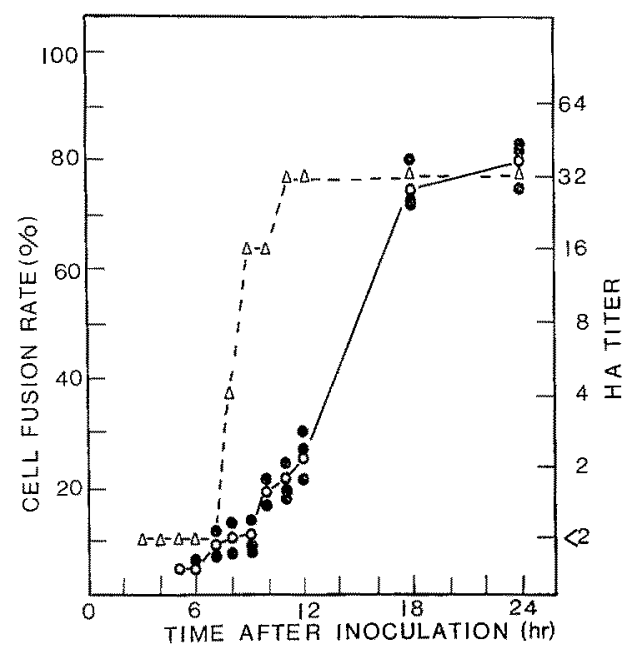

Fig. 1. Comparison of cell fusion ratio with HA development in the BALB/C-3T3 cell cultures infected with DVIM. The cell fusion ratio (o; $0-0$ average) was expressed as a percentage of total nuclei counted in fused cells against total nuclei counted in the same mieroscopic viewing area. HA $(\Delta-\cdots-\Delta)$ was titrated by conventional method

DVIM specific antigen was first detectable in tho cytoplasm of syncytia at 8 hours p.i. From Fig. 2 it can be seen that the antigens are restricted to the eytoplasm of the syncytium. Antigens were not detected in the nucleus at any time of viral infection. 


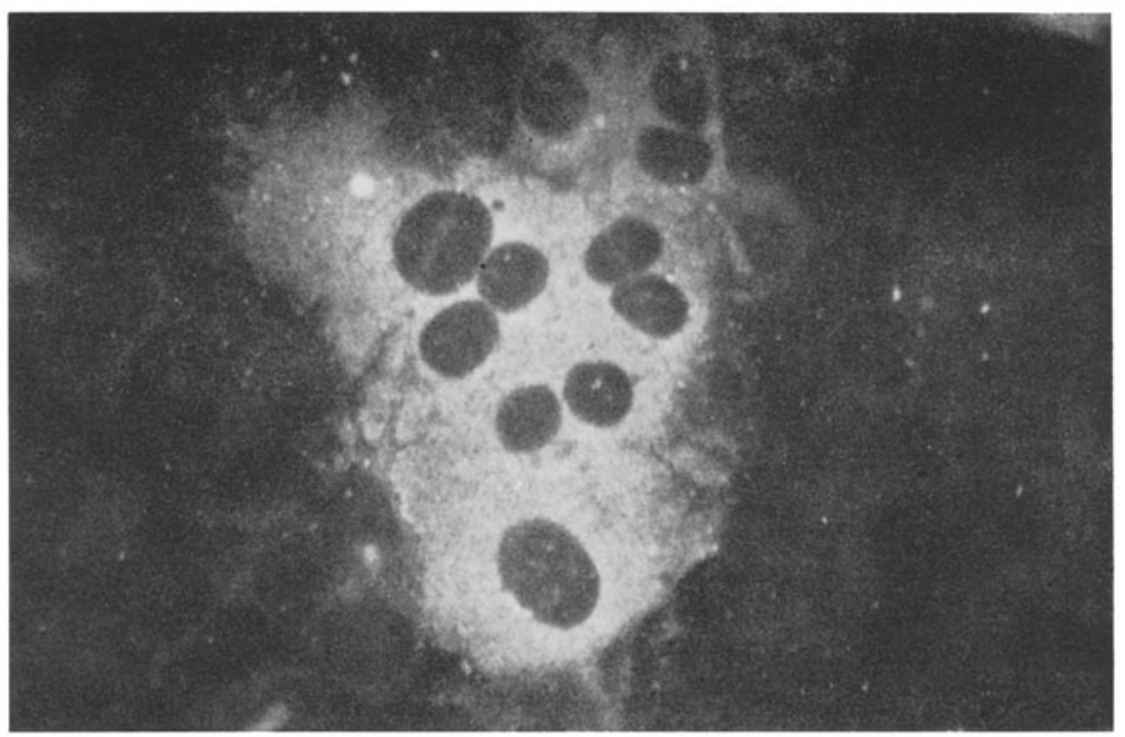

Fig. 2. Fluorescent-antibody staining of DVIM infected cells. At 10 hours post infection, the infected monolayer on coverslips was stained with fluorescent antibody by the indirect method

\section{Scanning Electron Microscopy (SEM)}

Surface details of BALB/c-3T3 cell cultures, pre- and post-infection with DVIM, were investigated by SEM.

The surface of uninfected cells were covered with microvilli (Fig. 3A), as previously shown for many cell lines, but following infection with DVIM (10 hours p.i.) the surface area of syncytia were shown to be covered with a large number of spherical buds (Fig. 3B). The buds were moderately pleomorphic in shape, approximately $100-130 \mathrm{~nm}$ in diameter. Particles of a similar size were not detected on the surface of uninfected cells. Therefore we conclude those particles are budding virions. This conclusion is further substantiated by the observation that mouse erythrocytes were exclusively adsorbed to syncytia. Moreover, as shown in Fig. $4 \mathrm{~A}$ the size of the syncytia could be delineated by the location of adsorbed erythrocytes. At a high magnification, a large number of particles were clearly visible in the area of hemadsorption (Fig. 4B).

\section{Growth Curve}

Fig. 5 shows the growth curve of DVIM in BALB/c-3T3 cells. The production of CAV was detected within 4 hours p.i., followed by a rapid exponential increase. At 6 hours p.i., CAV titer reached a maximum level $\left(10^{5.3}\right.$ TCID $\left._{50} / 0.1 \mathrm{ml}\right)$. The production of ECV was later than that of CAV, but the titer was $10^{5.3} \mathrm{TCID}_{50}$ / $0.1 \mathrm{ml}$ at 10 hours p.i. Although syncytium formation was very rarely detected. at 6 hours p.i., approximately 80 per cent of the cells were fused by 18 hour and detachment from the glass surface followed. 

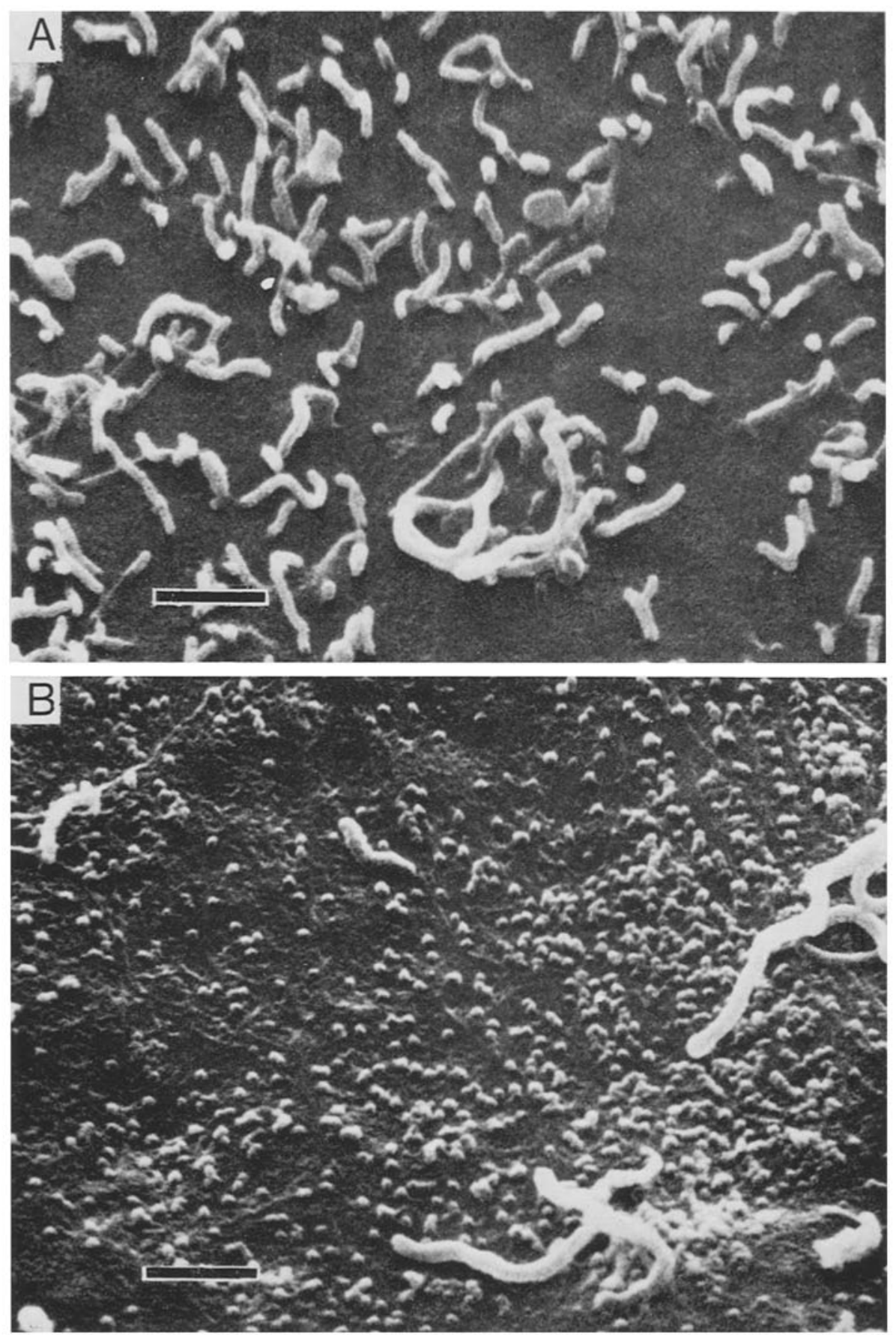

Fig. 3. Surface profile of DVIM uninfected $(A)$ and infected $(B)$ BALB/C-3T 3 cells, by scanning electron microscopy. Bar, $1000 \mathrm{~nm}$ 

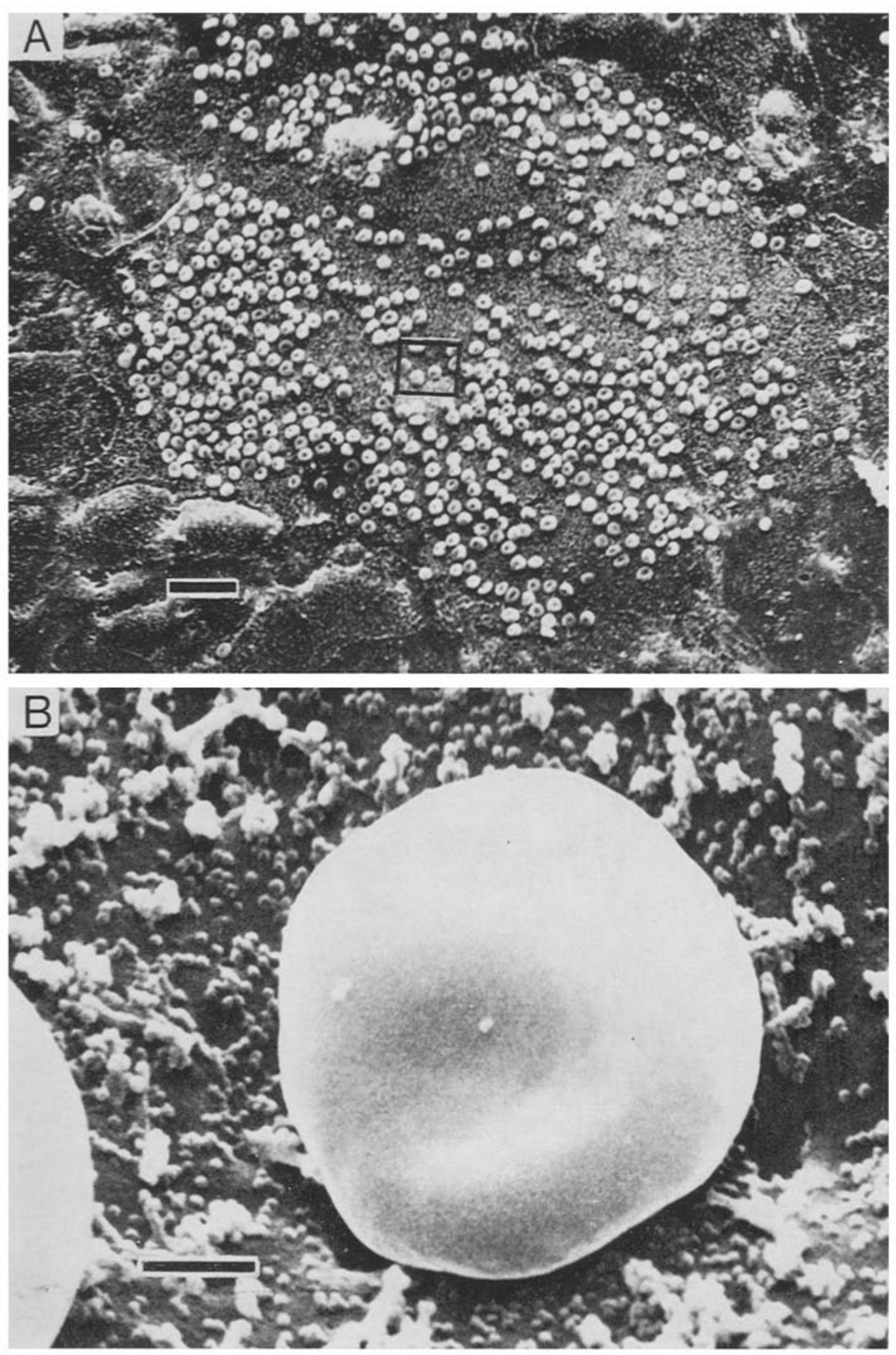

Fig. 4. Hemadsorbed syncytium, by scanning electron microscopy. (A) An entire surface profile of syncytium. Bar, $20 \mu \mathrm{m}$. (B) Higher magnification view of the center area of $(A)$. Bar, $1000 \mathrm{~nm}$ 
HA titers of CAV increased rapidly from 4 to 6 hours p.i. corresponding to a rapid increase in virus production from $10^{0.8}$ to $10^{5.3} \mathrm{TCTD}_{50} / 0.1 \mathrm{ml}$, and the titer continued to increase until 8 hours p.i. HA titers of ECV were delayed by approximately 2 hours compared to those of CAV. Infectivity of CAV and ECV decreased from 12 hours p.i., corresponding to rapid degeneration of infected cells and possibly virions, while the HA titer of ECV remained constant until 24 hours p.i. at $37^{\circ} \mathrm{C}$. The estimated time required for one step growth of DVIM was approximately 6 hours.

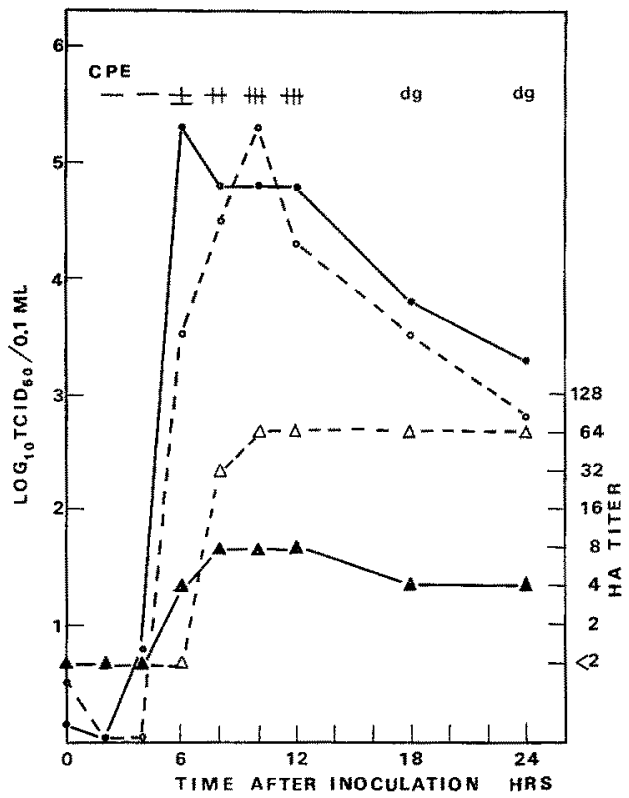

Fig. 5. Growth of DVIM in BALB/c-3T3 cells. Cell associated virus (•-—) and extracellular virus $(0-\ldots)$ were assayed as described in Materials and Methods. HA activity of cell associated virus $(\Lambda-\infty)$ and extracellular virus $(\Delta--\rightarrow \Delta)$ were also assayed. $d g$ cells degenerated

\section{Morphalogy of the Virus Particles}

An electron-micrograph of partially purified DVIM is shown in Fig. 6. The diameter of virions varied from 100 to $110 \mathrm{~nm}$, excluding the surface projections. The projections formed a fringe radiating from the viral envelope and they appeared to be club-shaped, $20 \mathrm{~nm}$ in length and $10 \mathrm{~nm}$ in width at the distal end of the projections. In addition, noticeable structures which consisted of apparent additional small granular projections were observed. These small projections were $5 \mathrm{~nm}$ in length and firmly fixed on the viral envelope. Purified virus particles, in most of the preparations, were only partially covered by club-shaped projections but always covered with small granular projections, even after a considerable period of sonication. 


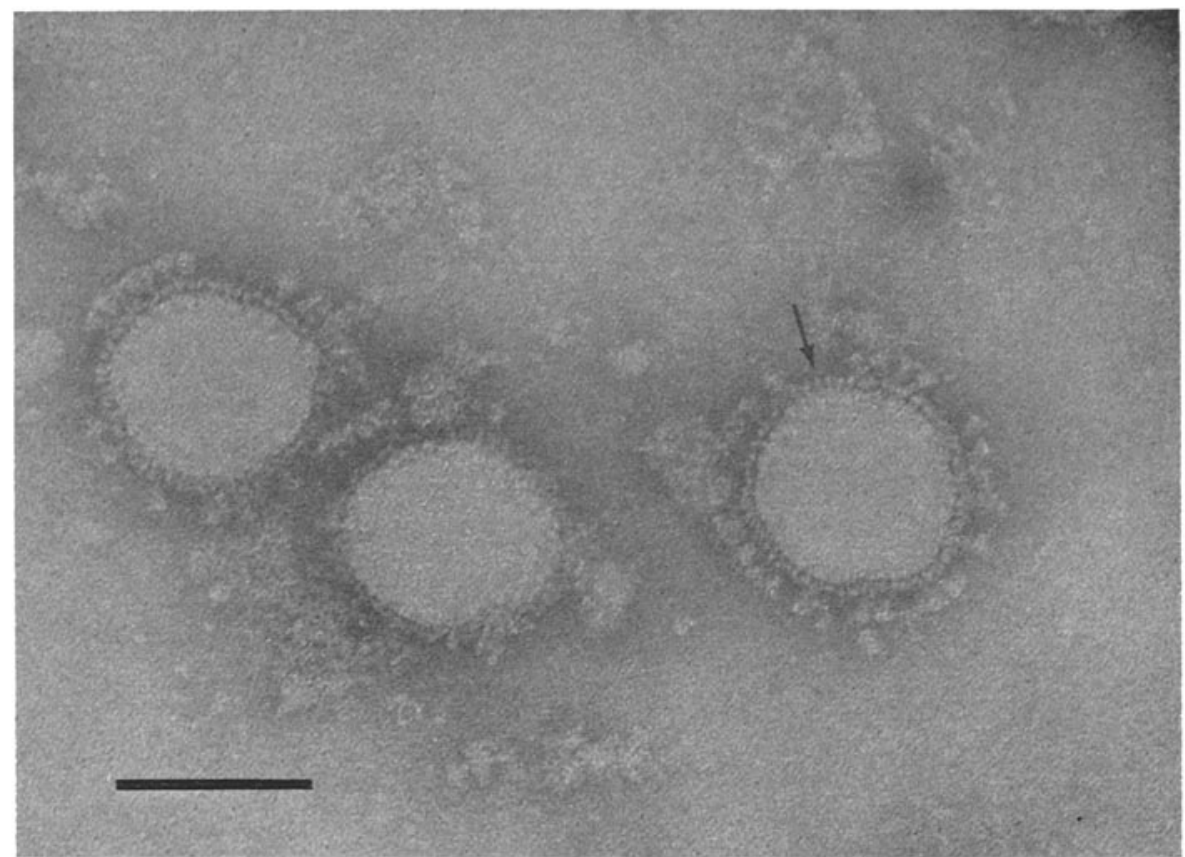

Fig. 6. A transmission electron micrograph of DVIM negatively stained with 2 per cent PTA. Arrow shows small projection. Bar, $100 \mathrm{~nm}$

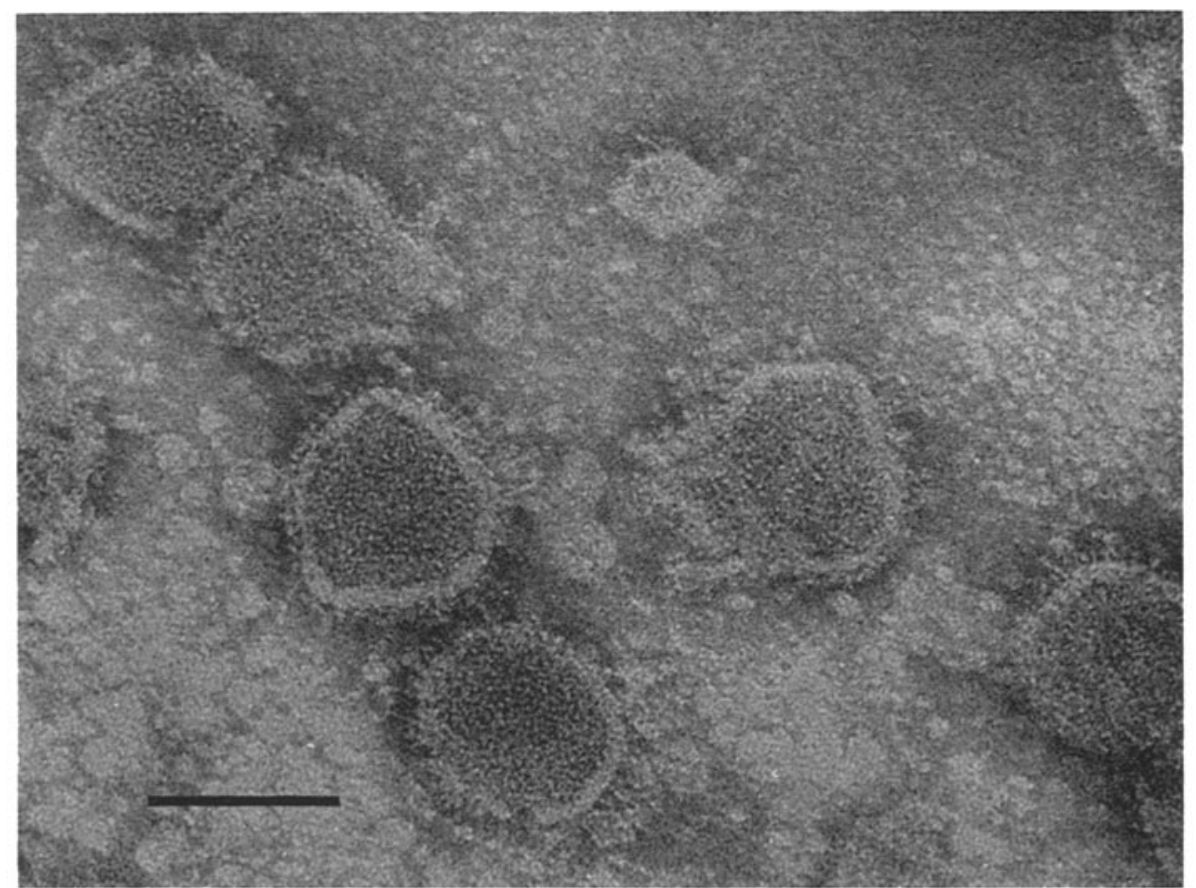

Fig. 7. A transmission electron micrograph of DVIM after sonication at $20 \mathrm{KHz}$ for 10 minutes. Virions were negatively stained with 2 per cent PTA. Bar, $100 \mathrm{~nm}$ 
Fig. 7 shows the negatively stained DVIM particles after sonication at $20 \mathrm{KHz}$ for 10 minutes. Although club-shaped projections had completely disappeared, small projections were still present on the surface of partially disrupted virions. Furthermore, the inner structure of the virion was clearly observed after sonication suggesting penetration of the stain. The thickness of the envelope was measured as $10 \mathrm{~nm}$ and a fine filamentous structure, irregularly tangled, was observed in broken virions.

\section{Diseussion}

Recently, some viral agents, which are responsible for diarrhea of new-borne mice, have been classified. Reovirus is a major cause of murine diarrhea (8). Epizootic diarrhea of infant mice (EDIM) virus is now classified as a rotavirus by HoLMEs el al. (15). Mouse hepatitis virus (MHV), a member of coronaviruses, has been described as a common cause of enteric infection in baby mice $(8,21)$. On the other hand, lethal intestinal virus of infant mice (LIVIM), first described by KRAFT, is probably the most important viral agent of diarrhea in new-born mice $(3,17)$, but there was no viral agent detected. However, the epidemiological and pathological characterization of diarrhea of new-borne mice is consistent with the recorded pathology of LIVIM, and suggests that a MHV could be the cause of this disease $(5,7,14,16)$.

Previous results reported by SATo et al. (22) indicated that the infectious agent (DVIM) isolated from the intestine of mice with diarrhea possesses RNA and lipid. The agent passes through a $100 \mathrm{~nm}$ filter but not a $50 \mathrm{~nm}$ filter. Serologically, DVTM was shown to be related to IBV and MHV-2 by a complement fixation test but they were clearly distinguishable from each other by neutralization assays. These observations suggested that this new isolate, DVIM, is a member of coronavirus. However, it was important to establish the morphological characteristics of purified DVIM, since coronavirus classification is established mainly by means of characteristic morphology at present.

The results presented in this report showed that diameter of vixion was approximately $100 \mathrm{~nm}$, excluding surface projections. Characteristic coronavirus projections attached to the virion were demonstrable. However morphologically DVIM appears to be slightly different in that additional small granular projections were observed. A similar small projection on enteric bovine coronavirus has been reported recently (4). But no additional projection has been detected on MHV-2, propagated and purified in the same manner as DVIM (data not shown). The morphological relationships of the two projections, club-shaped and granular, are at present not clear. However, it is possible that the club-shaped projection might be attached to the granular projection. Moreover, the HA activity of DVIM was only slightly affected by sonication, which suggests that the HA activity of DVIM might be associated with the small granular projection.

We showed by SEM that a large number of particles were present on the DVIM-induced syncytia but not on uninfected cells. The size of the particle was similar to that of negatively stained DVIM, while hemadsorption was restricted to the cells which possess surface particles. The surface profile of DVIMinfected cells has a prominent resemblance to the cells infected with ortho- or para-myxoviruses $(1,12,27)$. As described previously $(24)$, it is clear that the 
hemadsorption of DVIM was not due to the "pseudohemadsorption" (6). These observations suggest that DVIM particles are assembled and bud through the plasma membrane of syncytium.

In addition to these morphological properties, the existence of $\mathrm{HA}$ and receptor destroying activities as described previously (24), have not been reported for any of the other murine coronaviruses. Several studies of coronaviruses by the thin sections and transmissible electron microscopy show unequivocally that coronaviruses are formed by budding from the surface of intracellular cisterne $(2,10,13$, 20). The more detailed morphogenesis of DVIM remains to be investigated in future.

\section{Acknowledgments}

We wish to thank Dr. Kozaburo Sato, Central Laboratory, Shionogi Pharma. Co., Osaka, for his useful advices during this work.

\section{References}

1. Baker, R., Gordon, I., Stevenson, D.: Electron microscope study of hemadsorption in measles virus infection. Virology $27,441-445$ (1965).

2. Becker, W. B., MoIntosh, K., Dees, J. H., Chanock, R. M.: Morphogenesis of avian infectious bronchitis virus and a related human virus (strain $229 \mathrm{E}$ ). J. Virol. 1, 1019-1027 (1967).

3. Biggers, D. C., KraFt, L. M., Sprinz, H.: Lethal intestinal virus infection of mice (LIVIM). Amer. J. Pathol. 45, 413-422 (1964).

4. Bridger, J. C., Caul, E. O., Eqcuestone, S. I.: Replication of an enteric bovine coronavirus in intestinal organ cultures. Arch. Virol. 57, 43-51 (1978).

5. Broderson, J. R., Murphy, F. A, Hirrholzer, J C.: Lethal enteritis in infant mice caused by mouse hepatitis virus. Lab. Anim. Sci. 26, 824 (1976).

6. Bucknale, R. A., Kalica, A. R., Chanock, R. M.: Intracellular development and mechanism of hemadsorption of human coronavirus, OC43. Proc. Soc. exp. Biol. Med. 139, 811-817 (1972).

7. CARThEW, P.: Lethal intestinal virus of infant mice is mouse hepatitis virus. Vet. Rec. 101, 465 (1977).

8. Calisher, C. H., Rowe, W. P.: Mouse hepatitis, reo-3, and the Theiler viruses. Natl. Cancer Inst. Monogr. 20,67-75 (1966).

9. Caul, E. O., Paver, W. K., Crarke, S. K. R.: Coronavirus particles in faeces from patients with gastroenteritis. Lancet 1, 1192-1193 (1975).

10. Chasey, D., Alexander, D. J.: Morphogenesis of avian infeetious bronchitis virus in primary chick kidney cells. Arch. Virol. 52, 101-111 (1976).

11. Doyle, L. P., Hutchings, L. M. : A transmissible gastroenteritis in pigs. J. Amer. vet. Med. Ass. 108, 257-259 (1946).

12. Dud-NGUyen, H.: Hemadsorption of mumps virus examined by light and electron microseopy. J. Virol. 2, 494-506 (1968).

13. Hanre, D., Krndig, D. A., MANn, J.: Growth and intracellular development of a. new respiratory virus. J. Virol. 1, 810-816 (1967).

14. Hierholzer, J. C., Broderson, J. R., Murphy, F. A.: New strain of mouse hepatitis virus as the cause of lethal enteritis in infant mice. Infect. Immun. 24, $508-522(1979)$.

15. Holmes, I. H., Ruck, B. J., Bishop, R. F., Davidson, G. P.: Infantile enteritis viruses. Morphogenesis and Morphology. J. Virol. 16, 937-943 (1975).

16. Ishida, T., Taguchi, F., Lee, Y., Yamada, A., Tamura, T., FuJtwara, K.: Isolation of mouse hepatitis virus from infant mice with fetal diarrhea. Lab. Anim. Sci. 28, $269-276$ (1978).

17. Kraft, L. M.: An apparently new lethal virus disease of infant mice. Science 137, $282-283(1962)$. 
18. McIntosh, K.: Coronavirus; A comparative review. Curr. Top. Microbiol. Immunol. 63, 85-129 (1974).

19. Mebus, C. A., Stair, E. L., Rrodes, M. B., Twienaus, M. J.: Pathology of neonatal calf diarrhea induced by a coronavirus-like agent. Vet. Pathol. 10, $45-64$ (1973).

20. Oshiro, L. S., Schleble, J. H., LennetTe, E. H.: Electron microscopic studies of coronavirus. J. gen. Virol. 12, 161-168 (1971).

21. Rowe, W. P., Hartley, J. W., Capps, W. I.: Mouse hepatitis virus infection as a highly contagious, prevalent, enteric infection of mice. Proc. Soc. exp. Biol. Med. 112, 161-165 (1963).

22. Sato, K., Mard, M., WADA, T.: Some characteristics of corona-like virus isolated from infant mice with diarrhea and inflamentory submaxillary gland of rats (in Japanese). Virus 26, 97 (1976).

23. Sharpee, R. L., Mebds, C. A., Bass, E. P.: Characterization of a calf diarrhea coronavirus. Amer. J. Vet. Res. 37, 1031-1041 (1976).

24. Sugryama, K., Amano, Y.: Hemagglutination and structural polypeptides of a new coronavirus associated with diarrhea in infant mice. Arch. Virol. 66, 95$105(1980)$.

25. TaJima, N.: Morphology of transmissible gastro-enteritis virus of pigs. A possible member of coronaviruses. Arch. ges. Virusforsch. 29, 105-108 (1970).

26. Tyrrexix, D. A. J., Almeida, J. D., Berry, D. M., Cunningeram, C. H., Hamre, D., Hofstad, M. S., Malludoct, L., McIntosh, K.: Coronaviruses. Nature 220, 650 (1968).

27. Vogel, J., SHelokov, A.: Adsorption-hemagglutination test for influenza virus in monkey kidney tissue cultures. Science 126, 358-359 (1957).

Authors' address: Dr. K. Sugryama, Department of Microbiology, University of Alabama in Birmingham, University Station, Birmingham, AL 35294, U.S.A.

Received August 20, 1980 